\title{
Genome-wide identification and characterization of the fibrillin gene family in Triticum aestivum
}

\author{
Yaoyao Jiang Equal first author, 1, Haichao Hu ${ }^{\text {Equal first author, } 2 \text {, Yuhua Ma }}{ }^{3}$, Junliang Zhou ${ }^{\text {Corresp. } 3}$ \\ ${ }^{1}$ School of Forestry and Biotechnology, Zhejiang Agriculture and Forestry University, Hangzhou, China \\ 2 College of Agriculture and Food Science, Zhejiang Agriculture and Forestry University, Hangzhou, China \\ 3 Guizhou Institute of Pomological Sciences, Guizhou Academy of Agricultural Sciences, Guiyan, China \\ Corresponding Author: Junliang Zhou \\ Email address: gsszj12008@163.com
}

Background: The fibrillin ( $F B N)$ gene family is highly conserved and widely distributed in the photosynthetic organs of plants. Members of this gene family are involved in the growth and development of plants and their response to biotic and abiotic stresses. Wheat (Triticum aestivum), an important food crop, has a complex genetic background and little progress has occurred in the understanding of its molecular mechanisms. Methods: In this study, we identified 26 FBN genes in the whole genome of $T$. aestivum through bioinformatic tools and biotechnological means. These genes were divided into 11 subgroups and were distributed on 11 chromosomes of $T$. aestivum. Interestingly, most of the TaFBN genes were located on the chromosomes 2A, 2B and 2D. The gene structure of each subgroup of gene family members and the position and number of motifs were highly similar. Results: The evolutionary analysis results indicated that the affinities of FBNs in monocots were closer together. The tissue-specific analysis revealed that $T a F B N$ genes were expressed in different tissues and developmental stages. In addition, some TaFBNs were involved in one or more biotic and abiotic stress responses. These results provide a basis for further study of the biological function of FBNs. 
1 Genome-wide identification and characterization of the

2 fibrillin gene family in Triticum aestivum

3

6 1. Zhejiang Agriculture and Forestry University, School of Forestry and Biotechnology, 7 Hangzhou, Zhejiang, China

$8{ }^{2}$. Zhejiang Agriculture and Forestry University, College of Agriculture and Food Science, 9 Hangzhou, Zhejiang, China

3. Guizhou Academy of Agricultural Sciences, Guizhou Institute of Pomological Sciences, Guiyan, Guizhou, China

*Corresponding: Zhou Junliang, mailto:gsszj12008@163.com (JL.Z)

\# YY.J. and HC.H. contributed equally to this work.

\section{Abstract}

Background: The fibrillin $(F B N)$ gene family is highly conserved and widely distributed in the photosynthetic organs of plants. Members of this gene family are involved in the growth and development of plants and their response to biotic and abiotic stresses. Wheat (Triticum aestivum), an important food crop, has a complex genetic background and little progress has occurred in the understanding of its molecular mechanisms.

Methods: In this study, we identified $26 F B N$ genes in the whole genome of T. aestivum through bioinformatic tools and biotechnological means. These genes were divided into 11 subgroups and were distributed on 11 chromosomes of T. aestivum. Interestingly, most of the TaFBN genes were located on the chromosomes $2 \mathrm{~A}, 2 \mathrm{~B}$ and 2D. The gene structure of each subgroup of gene family members and the position and number of motifs were highly similar.

Results: The evolutionary analysis results indicated that the affinities of $F B N s$ in monocots were closer together. The tissue-specific analysis revealed that TaFBN genes were expressed in 
27

28

different tissues and developmental stages. In addition, some TaFBNS were involved in one or more biotic and abiotic stress responses. These results provide a basis for further study of the biological function of $F B N s$.

Subjects: Bioinformatics, Genomics, Plant Science

Keywords: Fibrillin, Triticum aestivum, Abiotic stress, Phylogenetic tree, Cis-regulatory elements

\section{Introduction}

Fibrillins (FBNs) are named after fibrils because these proteins were first detected in fibrils in the chromoplasts of dog rose (Rosa rugosa) and bell pepper (Capsicum annuum) fruit (Newman et al., 1989; Deruère et al., 1994; Kim et al., 2015). Since then, FBN proteins have been found in different organelles, including the plastoglobules (PGs) in the chloroplasts and algal eyespots. Therefore, members of the FBN protein family have been given many different names, including the plastid-lipid associated protein (PAP), the plastoglobule (PGL), the chloroplastic drought-induced stress protein of $34 \mathrm{kDa}$ (CDSP 34), and the chromoplast-specific carotenoid-associated protein (ChrC) (Pozueta-Romero et al., 1997; Ting et al., 1998; Kim et al., 2015). Fibrillins are located in the photosynthetic organs of cyanobacteria and some higher plants (Kim et al., 2015; Kim et al., 2017). Lundquist et al. (2012) identified 14 FBN genes in Arabidopsis by proteomic analysis, $50 \%$ of which were in the PGs, while others are mainly distributed in the stroma and thylakoid membranes (Lundquist et al., 2012; Kim et al., 2015).

So far, the FBN protein family is mainly composed of 12 subfamilies; 11 of these have been found in higher plants and one has been identified in algae (Lohscheider and Río Bártulos, 2016; Kim et al., 2017). The members of these subfamilies were found to have similar hydrophobic structures; however, the biophysical properties of these proteins are quite diverse, including proteins with molecular weights of 20-42 kDa and isoelectric point (pI) values of 4-9 (Vidi et al., 2006; Lundquist et al., 2012). These findings suggest that each FBN protein may have specific biological functions. In Arabidopsis thaliana, FBN proteins contain a conserved hydrophobic 
53

54

55

domain (lipocalin motif 1 ) in the $\mathrm{N}$-terminus and amino acid residues near the $\mathrm{C}$-terminus, including aspartic acid (Singh et al., 2010). Furthermore, Lohscheider and Río Bártulos (2016) predicted that the three-dimensional structure of FBNs is similar to that of lipocalin, with the ability to bind and transport small hydrophobic molecules (Lohscheider and Río Bártulos, 2016), which suggests that the FBN family may have similar biological functions (Singh et al., 2010; Francesc et al., 2015; Kim et al., 2015).

FBN proteins have a variety of important biological functions, such as participating in photosynthesis, the formation of lipoprotein structures, and responses to abiotic and biotic stresses (Kim et al., 2015). Initially, researchers found that FBNs are located on the outer surface of red pepper chromoplast fibrils by Immunogold electron microscopy (Deruère et al., 1994). Furthermore, fibril-like structures can be reconstituted in vitro from a mixture of FBN protein, lipids, and bicyclic carotenoids (Deruère et al., 1994; Kim et al., 2015). Compared to wild-type plants, RNAi-transgenic tomato plants with suppressed LeChrC (FBN1) accumulate 30\% fewer carotenoids (Leitner-Dagan et al., 2006; Singh et al., 2010). In addition, when the FBN5 gene was deleted in Arabidopsis thaliana and rice, mutant plants were more sensitive to light stress, and the levels of PQ-9 and PC-8 in the leaves were reduced (Kim et al., 2017). These results suggest that FBNs can regulate the formation of chromoplast fibrils and the accumulation of carotenoids. In addition to structural roles, fibrillin gene expression is also regulated by numerous abiotic and biotic stresses, especially oxidative stress (Youssef et al., 2010). For example, the expression of the Chrc (FBN1) is induced in cucumber leaves infected with Sphaerotheca fuliginea (Leitner-Dagan et al., 2006). Similar results were seen for tomato plants infected with the fungus Botrytis cinerea. However, the expression patterns of fibrillins are varied and complex during abiotic stress such as heat, cold, drought, high light and wounding treatment (Pruvot et al., 1996; Kuntz et al., 1998; Georg et al., 2001; Leitner-Dagan et al., 2006; Simkin et al., 2008). AtFBN1a expression was induced and AtFBN2 expression was repressed when subjected to drought or cold treatment (Laizet et al., 2004). High levels expression of fibrillin $(F B N 1)$ were observed in potato plants during water stress (Lee et al., 2007). Similarly, 
80

81

the mutants of $p g l l$ and $p g l 2$ were more sensitive to high light stress than was the wild-type in Synechocystis sp (Cunningham et al., 2010). Moreover, when LeChrC (FBN1), FBI4 and AtFBN4 were knocked down in tomato, apple, and Arabidopsis, the mutant plants were more susceptible to the phytopathogenic fungus Botrytis cinerea and pathogenic bacteria Erwinia amylovora and Pseudomonas syringae pv. tomato, respectively (Cooper et al., 2003; LeitnerDagan et al., 2006; Singh et al., 2010). Meanwhile, FBN gene expression is regulated by hormones, including gibberellic acid (GA), jasmonate, and abscisic acid, during plant growth and developmental stages, as well as when plants are subjected to stresses (Yang et al., 2006; Youssef et al., 2010; Kim et al., 2017). The accumulation of FBN proteins in the tomato flacca mutant plant was decreased, which was defective in ABA biosynthesis, when subjected to drought stress. The level of FBN protein can be induced by abscisic acid treatment (Gillet et al., 2001). Moreover, $F B N 1$ and $F B N 2$ proteins are involved in the jasmonate biosynthesis pathway in response to light and cold stress (Youssef et al., 2010). By contrast, FBN1 mRNA and protein levels declined in red pepper fruit when treated with gibberellic acid (Deruère et al., 1994). Wheat (Triticum aestivum L.) is an important food crop that is widely grown around the world. Approximately $40 \%$ of the global population depends on T. aestivum as their staple food (Paux et al., 2008; Han et al., 2019). Common T. aestivum is a heterogenous hexaploid containing A, B, and D genomes; therefore, the genome information is large and complex (Ling et al., 2013; Glover et al., 2015; Han et al., 2019). Moreover, owing to the complex genetic background of $T$. aestivum, only some genes regulating important agronomic and disease-related traits were reported. Therefore, the study of $T$. aestivum functional genomics is lagging far behind that of rice and corn. In recent years, high-quality wheat genome sequencing has been completed (International Wheat Genome Sequencing Consortium et al., 2018); this will play an important role in elucidating the molecular mechanisms involved in growth and development, resistance, and high yield (Pradhan et al., 2019; Rahimi et al., 2019).

Although there is increasing evidence that $F B N$ s play major roles in photosynthetic organisms, to date, they have been identified and characterized from only a few plant species. In 
107

108

109

110

111

112

113

114

115

116

117

118

119

120

121

122

123

124

125

126

127

128

129

130

131

132

addition, there are few studies on the function of FBN genes in wheat. The identification and functional characterization of the $F B N$ family in $T$. aestivum will contribute to elucidating the stress response mechanisms. In this study, we performed a genome-wide survey using the reported FBN protein sequences in the T. aestivum database. We identified $26 F B N$ genes in $T$. aestivum and used bioinformatic methods to analyze their biophysical properties, including gene structures and conserved motifs, as well as the chromosome distribution of the $F B N$ genes. In addition, we analyzed the expression profiles of $T a F B N$ genes in different tissues, at different developmental stages, and in response to abiotic and biotic stresses using the T. aestivum expression database. These results may provide a basis for studying the biological function of the $F B N$ gene in different growth and development stages of T. aestivum.

\section{Materials \& Methods}

\section{Plant material cultivation and treatments}

The common T. aestivum cultivar "Chinese spring" was used in this study. Triticum aestivum seeds were sterilized with $1 \% \mathrm{NaOCl}$ for $15 \mathrm{~min}$, rinsed thoroughly with distilled water five times, and soaked in distilled water overnight at room temperature $\left(18^{\circ} \mathrm{C}\right)$. The seeds were transferred to filter paper and germinated for three days. The seedlings were cultured in a nutrient solution and grown in a growth chamber with $16 \mathrm{~h}$ light $\left(22^{\circ} \mathrm{C}\right), 8 \mathrm{~h}$ dark $\left(18^{\circ} \mathrm{C}\right)$, and $50 \%$ humidity. The nutrient solution was replaced every three days at the growth stage. At 21 days old, the seedlings were treated with 20\% (m/V) PEG 6000 (Sigma-Aldrich, St. Louis, MO, USA) for $6 \mathrm{~h}$. Untreated seedlings were used as a control, and each treatment contained three independent biological replicates. The roots, shoots, and leaves were collected separately for further analysis at $1 \mathrm{~h}$ and $6 \mathrm{~h}$ after treatment.

\section{Identification of $\mathrm{TaFBN}$ genes}

We used the protein sequences of Arabidopsis thaliana FBN $(A t F B N)$ and Oryza sativa FBN $(O s F B N)$ genes as queries to perform a BLAST (E-value le $\left.{ }^{-10}\right)$ search against the $T$. aestivum genome database (genome assembly from IWGSC; http://ensembl.gramene.org/). We 
133

134

135

136

137

138

139

140

141

142

143

144

145

146

147

148

149

150

151

152

153

154

155

156

157

158

159

obtained a dataset of $T a F B N$ sequences and filtered out the redundant sequences. The protein sequences of the $A t F B N$ and $O S F B N$ genes were downloaded from the Arabidopsis Information Resource database (https://www.arabidopsis.org/) and the Rice Annotation Project database (https://rapdb.dna.affrc.go.jp/). Since a typical FBN protein is reported to contain a conserved PAP_fibrillin domain (PF04755), the online tools SMART (http://smart.embl-heidelberg.de/) and InterProScan (http://www.ebi.ac.uk/interpro/) were used to predict the functional domains of the potential TaFBN proteins. To verify our results, all of the proteins were compared to the PAP_fibrillin domain using the HMMER 3.0 program, with the default E-value (E-value $<10^{-3}$ ).

Proteins without the PAP_fibrillin domain were removed. The biophysical properties of the final TaFBN proteins were calculated using the ExPASy ProtParam tool (https://web.expasy.org), including the theoretical values of $\mathrm{pI}$, relative molecular mass, and the grand average of hydrophobicity (GRAVY). The subcellular localization of TaFBNs was analyzed using ProComp (http://linux1.softberry.com) and WoLF PSORT II (https://www.genscript.com/wolf-psort.html). In addition, the signal peptide and chloroplast transit peptides of the $T a F B N$ genes were predicted using the SignalP 4.1 server (http://www.cbs.dtu.dk/services/SignalP-4.1/) and ChloroP 1.1 server (http://www.cbs.dtu.dk/services/ChloroP/).

\section{Multiple sequence alignments and phylogenetic analysis}

Full-length protein sequences of the $F B N$ gene family members identified in 13 plant species, including eight monocotyledon species and five dicotyledon species, were downloaded from the NCBI database (https://www.ncbi.nlm.nih.gov/), the Ensembl Plants database (genome assembly from IWGSC; http://ensembl.gramene.org/), and the Phytozome v12.1 database (https://phytozome.jgi.doe.gov/pz/portal.html). The full-length protein sequences of these $F B N$ genes were aligned using MAFFT software (https://mafft.cbrc.jp/alignment/server/). Based on FASTA files, a neighbor-joining phylogenetic tree was constructed using Molecular Evolutionary Genetics Analysis (MEGA) version 7.0 software with 1000 bootstrap replicates. The phylogenetic tree we constructed in this study belongs to the phylogram tree. The phylogram 
160

161

162

163

164

165

166

167

168

169

170

171

172

173

174

175

176

177

178

179

180

181

182

tree is a branching diagram assumed to be an estimate of a phylogeny, branch lengths are proportional to the amount of inferred evolutionary change. Low support nodes $(<50)$ was collapsed and high support nodes $(>99)$ used a symbol $(*)$ in phylogenetic tree.

\section{Analysis of gene structures and conserved motifs}

To investigate the structure of $T a F B N$ genes, we used the Gene Structure Display Server 2.0 database (http://gsds.cbi.pku.edu.cn/) to analyze the distribution of exons and introns in TaFBN genes. Conserved motifs were predicted using the Multiple EM for Motif Elicitation (MEME) database (http://alternate.meme-suite.org/; the number of motifs was set to 10 and the motif width was set to 6-50).

\section{Analysis of the cis-regulatory element of $F B N$ gene promoters}

In this study, 2000-bp sequences upstream of the translational start sites of the TaFBN genes were set as promoter sequences. PlantCARE software

(http://bioinformatics.psb.ugent.be/webtools/plant care/html/) was used to predict the cisregulatory elements based on these promoter sequences. The distribution of cis-regulatory elements in the promoter of the TaFBN gene was displayed using TBtools software (https://github.com/CJ-Chen/TBtools) (Chen et al., 2018).

\section{Analysis of $T a F B N$ gene expression patterns}

The expression profile data used in this study were obtained via the Wheat Expression Browser database (http://www.wheat-expression.com/) (Philippa et al., 2016; Ricardo et al., 2018). We searched for $F B N$ genes on the website using the gene ID as query terms. The expression of $T a F B N \mathrm{~s}$ in different tissues, at different developmental stages, and under different abiotic and biotic stress conditions (including drought, cold, heat, and stripe rust) were analyzed. The results were presented as heatmaps, with different colors representing the absolute signal values. The color scale of the heatmap was given in $\log _{2}$ ratio values. The cultivar used in the gene expression profiles analysis was "Chinese spring".

\section{Total RNA isolation and real-time PCR analysis}

Total RNA from different tissues was extracted using TRIzol Reagent (Invitrogen). The 
187

188

189

190

191

192

193

194

195

196

197

198

199

200

201

202

203

204

205

206

207

208

209

210

211

212

213

total RNA was treated with RNase-free DNase I for 15 min to remove the remaining genomic DNA. First-strand cDNA was synthesized according to the manufacturer's instructions (TOYOBO, Kita-ku, Osaka, Japan), diluted 20 times, and used as a template for quantitative real-time PCR (qRT-PCR), which was performed using AceQ qPCR SYBR Green Master Mix (Vazyme, Nanjing, China). For an endogenous control, we used the T. aestivum actin gene (AB181991). At least three biological replicates, with three technical replicates each, were used for each treatment. Relative expression levels were calculated using the comparative $2^{-\Delta \Delta C t}$ method (Willems et al., 2008). The TaFBN primers used for qRT-PCR are listed in Table S1.

\section{Results}

\section{Identification and characterization of $F B N$ genes in $T$. aestivum}

In this study, a total of $26 \mathrm{FBN}$ genes were identified in T. aestivum, which we named TaFBN-A1-TaFBN-D10 according to their genome location (Table 1). The TaFBN characteristics, including the chromosomal position, intron number, gene length, number of amino acids, molecular mass, CDS, subcellular localization, signal peptide, and instability index, are listed in Table 1. As shown in Table 1, the TaFBN protein sequences ranged from 219 to 402 amino acids and the molecular weights ranged from 23.75 to $43.59 \mathrm{kDa}$. The prediction of subcellular locations indicated that 18 TaFBNs were located in the chloroplasts and eight were located extracellularly. At present, GRAVY values are an important index of measuring protein hydrophobicity. The GRAVY values of most TaFBN proteins, except TaFBN-A1, TaFBN-B1, and $T a F B N-B 6$, were negative, suggesting that they are hydrophilic. Meanwhile, the prediction results showed that no signal peptides were found in any TaFBN proteins, but all TaFBN proteins contain chloroplast transit peptides.

\section{Gene structure analysis of $\mathrm{TaFBN}$ genes}

To gain insight into the evolution of the TaFBN gene family, a diagram of the TaFBN exonintron gene structure was constructed based on the cDNA and genomic DNA sequence information (Supplementary text 1) using the Gene Structure Display Server (Figure. 1b). A neighbor-joining phylogenetic tree was also constructed to explore the evolutionary relationship 
214

215

216

217

218

219

220

221

222

223

224

225

226

227

228

229

230

231

232

233

234

235

236

237

238

239

240

and the phylogenetic classification of the $F B N$ genes in wheat. Gene structure analyses indicated that homologous genes had similar exon-intron distribution patterns (Fig. 1b). However, the number of introns in different $T a F B N$ gene family members varied greatly (ranging from 2 to 10 introns), while there was almost no difference between members of the same subfamily. We found that all TaFBN genes contained a conserved PAP_FBN domain (PF04755), and the distribution of the domains was consistent with the genetic homology (Fig. 1c). These results suggested that members of the same subfamily may have similar biological functions. In addition, we used the MEME online tool to analyze the conserved motifs of the TaFBN genes; the results showed that all TaFBN members contained five to nine conserved motifs (Fig. 2). The logo representation of the 10 conserved motifs identified for the proteins encoded by the TaFBN genes is described in Supplementary Fig. 1. Figure 2 showed that motif 1, motif 2, motif 3, motif 4, and motif 5 were highly conserved and widely distributed in all TaFBN proteins. The motif/domain analysis revealed that motif 1 contained conserved amino acid residues in the Cterminal and motif 3 contained a conserved lipocalin motif (Supplementary Fig. 2). The types and distribution of the conserved motifs may be the reason for the functional diversity of the TaFBNs.

\section{Phylogenetic and evolutionary analysis of $\mathrm{TaFBN}$}

An unrooted phylogenetic tree was constructed for $183 \mathrm{FBN}$ genes from eight monocotyledon species (with 26 FBNs from T. aestivum, nine from Oryza sativa, 11 from Zea mays, 10 from Sorghum bicolor, nine from Panicum hallii, 20 from Panicum virgatum, 10 from Setaria italica, and eight from Hordeum vulgare) and five dicotyledon species (with 14 FBNS from A. thaliana, 12 from Brassica oleracea var. capitata, 11 from Nicotiana tabacum, 21 from Glycine max, and 22 from Coffea arabica) to study the evolutionary relationships of the TaFBN members (Fig. 3). Based on the $F B N$ gene characteristics of $A$. thaliana, these $F B N$ genes can be classified into 11 subfamilies (Group 1 to Group 11). Interestingly, the members of the TaFBNs were identified into nine subfamilies, each subfamily containing two or three $F B N$ genes. The analysis also revealed that the $F B N$ genes in monocots (i.e., T. aestivum, $O$. sativa, Z. mays, $P$. 
241 hallii, and S. bicolor) were more closely related than those of the dicots (i.e., A. thaliana, $B$.

242 oleracea var. capitata, and N. tabacum).

243 Analysis of $\mathrm{TaFBN}$ cis-regulatory elements

244 To further identify the cis-regulatory elements located upstream of the TaFBN genes, 2000-

245 bp sequences upstream from the translational start sites of putative TaFBN gene families were

246 analyzed using the PlantCARE tool. As shown in Fig. 4, many cis-regulatory elements were

247 identified in the promoters of the TaFBN genes. These cis-regulatory elements can be divided

248 into three types: hormone response elements, stress response-related elements, and light

249 response-related elements. The hormone response elements, including the methyl jasmonate

250 (MeJA)-responsive, abscisic acid-responsive, gibberellin-responsive, salicylic acid-responsive,

251 and auxin-responsive elements, were widely distributed in promoters of the TaFBNs. The

252 responses to abiotic stress were the light response-related, low temperature response-related, and

253 drought stress-related response elements. These results suggested that TaFBN genes may be

254 involved in photosynthesis, stress responses, and maintaining the hormone balance in plants,

255 thereby improving the chances for organisms to escape or better cope with the damaging effects

256 of adverse environmental conditions.

257

258

259

260

261

262

263

264

265

266

267

\section{Tissue specific expression patterns of $\mathrm{TaFBNs}$ at different developmental stages}

To explore the tissue-specific expression patterns of TaFBN genes at different growth and developmental stages in T. aestivum, publicly available expression data sets for the $26 \mathrm{TaFBN \textrm {s }}$ were analyzed. The transcription levels in various $T$. aestivum tissues, including the root, shoot, anther, spikelet, and leaf, were examined. Most of the $T a F B N$ genes were detected in at least two or more different tissues. The results suggested that $T a F B N$ genes may be widely expressed in wheat tissues (Fig. 5a). However, the expression levels of TaFBN genes varied among the different tissues. The expression levels of the TaFBNs in the tissues with high chlorophyll contents (leaf, shoot, and internode) were significantly higher than those in other tissues. As shown in Fig. 5b, the expression levels of TaFBN were notably different at different developmental stages. The genes TaFBN-A1, TaFBN-B1, TaFBN-A2, TaFBN-B2, TaFBN-D2, 
268

269

270

271

272

273

274

275

276

277

278

279

280

281

282

283

284

285

286

287

288

289

290

291

292

293

294

$T a F B N-A 3, T a F B N-A 6, T a F B N-B 6$, and $T a F B N-D 6$ were highly expressed at all developmental stages. However, the expression levels of TaFBN-B4, TaFBN-D5, TaFBN-A9, TaFBN-B9, and $T a F B N-D 9$ were inhibited at all developmental stages. The expression levels of other TaFBN genes did not change significantly during any developmental stage. These data indicated that $T a F B N$ genes have tissue-specific expression patterns, and some $T a F B N$ genes play a vital role in the growth and development of T. aestivum.

\section{Expression profiles of $\mathrm{TaFBN}$ genes in response to abiotic stresses}

To further clarify the potential functions of $T a F B N$ genes under abiotic stress, the expression levels of $T a F B N$ genes were analyzed under drought, stripe rust, cold and heat conditions. Most of the TaFBN genes were shown to be involved in the response to one or more abiotic stresses (Fig. 6). The transcripts of TaFBN-A1, TaFBN-B1, TaFBN-A2, TaFBN-B2, $T a F B N-D 2$, and $T a F B N-B 6$ were significantly upregulated by drought, stripe rust, cold, and heat treatments. However, the expression levels of TaFBN-A5, TaFBN-B5, TaFBN-D5, TaFBN-A9, $T a F B N-B 9, T a F B N-D 9, T a F B N-A 10, T a F B N-B 10$, and $T a F B N-D 10$ were slightly downregulated under drought, stripe rust and heat stresses. In addition, most of the TaFBN genes were upregulated after $12 \mathrm{~h}$ of drought treatment and $11 \mathrm{~d}$ of stripe rust infection. Interestingly, almost all TaFBN genes had a high level of expression under cold stress. Other TaFBNs were induced to express under some of the stress conditions. The transcription levels of the tested TaFBN genes were significantly downregulated under drought stress conditions. These results indicated that $T a F B N$ genes might participate in response to abiotic stresses, especially drought, stripe rust, cold and heat stress in T. aestivum.

\section{Validation of TaFBNs by qRT-PCR}

To further detect the expression levels of the TaFBN genes in different tissues, we selected nine representative genes from the TaFBN gene family ( $T a F B N-A 1, T a F B N-B 1, T a F B N-A 2$, TaFBN-B2, TaFBN-D2, TaFBN-B5, TaFBN-B6, TaFBN-A9, TaFBN-B9, and TaFBN-D9) based on their expression profile, and analyzed their expression levels using qRT-PCR (Fig. 7a). The results showed that the expression of nine $T a F B N \mathrm{~s}$ in the leaves and shoots was significantly 
295 higher than that in the roots. We also analyzed the TaFBN gene expression in leaves under 296 drought stress in T. aestivum seedlings (Fig. 7b). The results suggested that the expressions of 297 some TaFBN genes, such as TaFBN-A1, TaFBN-B1, TaFBN-A2, TaFBN-B2, TaFBN-D2 and $298 T a F B N-B 5$, were induced at different time points under drought stress. However, $T a F B N-A 1$, $299 T a F B N-B 1, T a F B N-A 2$, and $T a F B N-B 2$ displayed downregulation after drought treatment. In 300 addition, as the treatment time increased, the expression level was significantly upregulated or 301 downregulated. These results are consistent with the data of the above expression profiles.

302

303

304

305

306

307

308

309

310

311

312

313

314

315

316

317

318

319

320

321

\section{Discussion}

In this study, we identified $26 \mathrm{FBN}$ genes in the T. aestivum genome. These genes were distributed on 11 chromosomes and had molecular masses ranging from 23.75 to $43.59 \mathrm{kDa}$ and pI values ranging from 4.59 to 9.61 . This diversity suggested that TaFBN genes may have specific biological functions in different metabolic processes. Furthermore, the results indicated that most of the $\operatorname{TaFBN}$ genes were located on the chloroplast and contained chloroplast transit peptides. This provided strong evidence that various FBNs might participate in photosynthesis. The overall hydrophobicity of the protein sequences were calculated with GRAVY, with higher positive GRAVY values indicating a greater level of hydrophobicity (Faya et al., 2015). Almost all of the TaFBN genes' GRAVY values were negative, which meant that most of the proteins were hydrophilic. In contrast, previous studies have reported that the $F B N$ family can bind to and transport small hydrophobic molecules in A. thaliana (Singh and McNellis., 2011; Kim et al., 2015). However, the specific spatial structure and the percentage of hydrophobic residues may affect the hydrophobicity of proteins (Dyson et al., 2004). Therefore, these different results may reflect the biological function diversity of the $\operatorname{TaFBN}$ genes.

To analyze the evolutionary relationships of the $F B N$ genes, we constructed a phylogenetic tree with 183 FBNs from T. aestivum, O. sativa, S. bicolor, Z. mays, P. hallii, P. virgatum, S. italica, H. vulgare, A. thaliana, B. oleracea var. capitata, N. tabacum, G. max, and C. arabica. These $F B N$ genes were divided into 11 subfamilies using the classification method described for FBN in A. thaliana (Singh and McNellis., 2011). In addition, gene family members of TaFBN 
322

323

324

325

326

327

328

329

330

331

332

333

334

335

336

337

338

339

340

341

342

343

344

345

346

347

348

were always clustered together with monocots in general, such as H. vulgare, O. sativa, Z. mays and S. bicolor. The similar exon-intron structures and the number of conserved motifs were observed in the same subgroups. These results suggested that the $F B N$ genes located in the same branch may have similar biological functions in these monocots. At the same time, the evolutionary analysis provides a solid foundation for further functional studies on $F B N$ genes in wheat.

Gene expression levels in different tissues and at different developmental stages may be determined by gene function. Previous studies have shown that FBNS are regulated by a variety of biological and environmental factors at different growth and developmental stages (Singh and McNellis, 2011). We analyzed the expression patterns of the TaFBN gene family in T. aestivum during different growth and development stages, and under biotic and abiotic stresses through publicly available gene expression data. We obtained 26 TaFBN gene expression profiles, which showed that most of the genes were highly expressed in the leaf, shoot, and internode. Similar results have been reported in potato, Arabidopsis, and Brassica rapa (Monte et al., 1999; Kim et al., 2001; Yang et al., 2006). Furthermore, the expression profile data suggested that TaFBN-A1, $T a F B N-B 1, T a F B N-A 2, T a F B N-B 2, T a F B N-D 2$, and TaFBN-B6 expressions were strongly induced under drought, stripe rust, cold, and heat stresses, but TaFBN-A5, TaFBN-B5, TaFBND5, TaFBN-A9, TaFBN-B9, TaFBN-D9, TaFBN-A10, TaFBN-B10, and TaFBN-D10 expressions were slightly inhibited under these stresses. In addition, other TaFBNs responded to one or more stresses. These was some evidence that the level of FBN proteins, such as FBN1a, FBN1b and $F B N 2$, increases in the leaves of rice, Arabidopsis, Brassica and potato plants subjected to drought and cold stress (Gillet et al., 2001; Kim et al.,2001; Laizet et al., 2004; Lee et al., 2007 ). Furthermore, the accumulation of the FBN1 protein in the tomato flacca mutant, which is defective in ABA biosynthesis, was significantly reduced compared to the wild type during drought stress (Gillet et al., 2001). We obtained similar results in wheat plants subjected to drought stress. It is possible that $F B N$ gene expression was regulated through endogenous ABA concentrations in response to numerous stresses (Singh and McNellis, 2011). Transcription 
349 factors participate in various biological processes by regulating the expression of downstream

350

351

352

353

354

355

356

357

358

359

360

361

362

363

364

365

366

367

368

369

370

371

372

373

374

375 gene cis-regulatory elements (Ning et al., 2017). In this study, many cis-regulatory elements were detected in the promoter sequences of the $T a F B N$ genes. These elements contained light response-related elements, drought response-related elements, and hormone response elements, such as MeJA, abscisic acid, gibberellic acid, salicylic acid, and auxin. Interestingly, all TaFBN genes included many light response-related elements. For example, Rey et al. (2000) found that overexpressing FBN1 can promote plant height and flowering under high light levels in tobacco (Rey et al., 2000; Singh and McNellis., 2011). Leitner-Dagan et al. (2006) showed that FBN gene expression and carotenoid accumulation in the flower tissue of the cucumber increased during GA treatment, and GA-responsive elements were found on the FBN promoter sequences (Leitner-Dagan et al., 2006). By contrast, auxin (IAA) can delay the accumulation of FBN protein in bell pepper fruit, but abscisic acid (ABA) can promote this process (Deruère et al., 1994; Singh and McNellis, 2011). Although the expression patterns of TaFBN genes were varied and complex, overall, these genes had similar functions in plant stress resistance and chromoplast development (Singh and McNellis, 2011).

\section{Conclusion}

In this study, we identified $26 F B N$ genes in T. aestivum using a genome-wide screening approach. Based on their phylogenetic relationships, these $F B N$ genes were classified into 11 subfamilies. The $T a F B N$ gene structures and conserved motifs were highly conserved in the same subgroup. Many cis-regulatory elements were found in the TaFBN gene promoter sequences, which showed that the expression of $T a F B N$ genes was regulated by various hormones and environmental factors. Moreover, almost all $T a F B N$ genes were highly expressed in the leaf, shoot, and internode. The expression profiling data suggest that TaFBN-A1, TaFBN$B 1, T a F B N-A 2, T a F B N-B 2, T a F B N-D 2$, and $T a F B N-B 6$ were responsive to many biotic and abiotic stresses. These results can help us to clarify the structural and functional relationships among $T a F B N$ gene family members. 


\section{References}

378 Chen CJ, Xia R, Chen H, He YH. 2018. TBtools, a Toolkit for Biologists integrating various 379 HTS-data handling tools with a user-friendly interface. bioRxiv DOI: 10.1101/289660.

380 Cooper B, Clarke JD, Budworth P, Kreps J, Hutchison D, Park S. 2003. A network of rice genes

associated with stress response and seed development. Proceedings of the National Academy of Sciences of the United States of America 100(8):4945-4950 DOI: 10.1073/pnas.0737574100.

Cunningham FX, Tice AB, Pham C, Gantt E. 2010. Inactivation of genes encoding plastoglobulin-like proteins in Synechocystis sp. pcc 6803 leads to a light-sensitive phenotype. Journal of Bacteriology 192(6):1700-1709 DOI: 10.1128/JB.01434-09.

Deruère J, Römer S, d'Harlingue A, Backhaus RA, Kuntz M, Camara B. 1994. Fibril assembly and carotenoid overaccumulation in chromoplasts: a model for supramolecular lipoprotein structures. Plant Cell 6:119-133 DOI: 10.2307/3869680.

Dyson MR, Shadbolt SP, Vincent KJ, Perera RL, McCafferty J. 2004. Production of soluble mammalian proteins in Escherichia coli: identification of protein features that correlate with successful expression. BMC Biotechnology 4:32 DOI: 10.1186/1472-6750-4-32.

Faya N, Penkler DL, Tastan Bishop Ö. 2015. Human, vector and parasite hsp90 proteins: a comparative bioinformatics analysis. FEBS Open Bio 5(1):916-927 DOI: 10.1016/j.fob.2015.11.003.

Francesc HG, Albert B. 2015. A hydrophobic proline-rich motif is involved in the intracellular targeting of temperature-induced lipocalin. Plant Molecular Biology 88:301-311 DOI: 10.1007/s11103-015-0326-X.

Georg L, Nathalie Mh, Mélanie B, Stephan C, Noëlle B, Marcel K, Pascal, Rey. 2001. Accumulation of plastid lipid-associated proteins (fibrillin/CDSP34) upon oxidative stress, 
401

402

403

404

405

406

407

408

409

410

411

412

413

414

415

416

417

418

419

420

421

422

423

424

425

426

427

ageing and biotic stress in Solanaceae and in response to drought in other species. Journal of Experimental Botany (360):360 DOI: 10.1093/jexbot/52.360.1545.

Gillet B, Beyly A, Peltier G, Rey P. 2001. Molecular characterization of CDSP 34, a chloroplastic protein induced by water deficit in Solanum tuberosum L. plants, and regulation of CDSP 34 expression by ABA and high illumination. Plant Journal 16(2):257262 DOI: 10.1046/j.1365-313x.1998.00292.x.

Glover NM, Daron J, Pingault L, Vandepoele K, Paux E, Feuillet C, Choulet F. 2015. Smallscale gene duplications played a major role in the recent evolution of wheat chromosome 3B. Genome Biology 16(1):188 DOI: 10.1186/s13059-015-0754-6.

Han Z, Liu Y, Deng X, Liu D, Liu Y, Hu Y. 2019. Genome-wide identification and expression analysis of expansin gene family in common wheat (Triticum aestivum L.). BMC Genomics 20(1):101 DOI: 10.1186/s12864-019-5455-1.

International Wheat Genome Sequencing Consortium. 2018. Shifting the limits in wheat research and breeding using a fully annotated reference genome. Science 361 eaar7191 DOI: 10.1126/science.aar7191.

Kim EH, Lee Y, Kim HU. 2015. Fibrillin 5 is essential for plastoquinone-9 biosynthesis by binding to solanesyl diphosphate synthases in Arabidopsis. The Plant Cell 27: 2956-2971 DOI: $10.1105 /$ tpc.15.00707.

Kim EH, Lee DW, Lee KR, Jung SJ, Jeon JS, Kim HU. 2017. Conserved function of fibrillin5 in the plastoquinone-9 biosynthetic pathway in Arabidopsis and rice. Frontiers in Plant Science 8:1197 DOI: 10.3389/fpls.2017.01197.

Kim HU, Wu SS, Ratnayake C, Huang AH. 2001. Brassica rapa has three genes that encode proteins associated with different neutral lipids in plastids of specific tissues. Plant Physiology 126:330-341 DOI: 0.2307/4279891.

Kuntz M, Chen HC, Simkin AJ, Römer S, Bramley PM. 1998. Upregulation of two ripeningrelated genes from a non-climacteric plant (pepper) in a transgenic climacteric plant (tomato). Plant Journal 13(3):351-361 DOI: 10.1046/j.1365-313X.1998.00032.x. 
428 Laizet Y, Pontier D, Mache, Régis, Kuntz M. 2004. Subfamily organization and phylogenetic 429 origin of genes encoding plastid lipid-associated proteins of the fibrillin type. Journal of $430 \quad$ Genome Science \& Technology 3(1):19-28 DOI: info:doi/10.1166/gl.2004.038.

431 Lee DG, Ahsan N, Lee S-H, Kang KY, Lee JJ, Lee B-H. 2007. An approach to identify cold432 induced low-abundant proteins in rice leaf. Comptes Rendus Biologies 330(3):0-225 DOI: $433 \quad$ 10.1016/j.crvi.2007.01.001.

434 Leitner-Dagan Y, Ovadis M, Shklarman E, Elad Y, Rav David D, Vainstein A. 2006. Expression 435 and functional analyses of the plastid lipid-associated protein CHRC suggest its role in 436 chromoplastogenesis and stress. Plant Physiology 142(1):233-244 DOI: 10.2307/20205918. 437 Ling HQ, Zhao S, Liu D, Wang J, Sun H, Zhang C. 2013. Draft genome of the wheat A-genome 
455 Paux E, Legeai F, Guilhot N, Adam-Blondon AF, Alaux M. 2008. Physical mapping in large 456 genomes: accelerating anchoring of BAC contigs to genetic maps through in silico analysis. Functional \& Integrative Genomics 8(1):29-32 DOI: 10.1007/s10142-007-0068-1.

458

459

460

461

462

463

464

465

466

467

468

469

470

471

472

473

474

475

476

477

478

479

480

Philippa B, Ricardo RG, Cristobal U. 2016. expVIP: a customisable RNA-seq data analysis and visualisation platform. Plant Physiology 170(4):2172-2186 DOI: 10.1104/pp.15.01667.

Pozueta-Romero J, Rafia F, Houlné G, Cheniclet C, Carde JP, Schantz ML, Schantz R. 1997. A ubiquitous plant housekeeping gene, PAP, encodes a major protein component of bell pepper chromoplasts. Plant Physiology 115:1185-1194 DOI: 10.1104/pp.115.3.1185.

Pradhan S, Babar MA, Robbins K, Bai G, Mason RE, Khan J, Shahi D, Avci M, Guo J, Maksud HM, Bhatta M, Mergoum M, Asseng S, Amand PS, Gezan S, Baik BK, Blount A, Bernardo A. 2019. Understanding the Genetic Basis of Spike Fertility to Improve Grain Number, Harvest Index, and Grain Yield in Wheat Under High Temperature Stress Environments. Frontiers in Plant Science 10:1481 DOI: 10.3389/fpls.2019.01481.

Pruvot G, Cuiné S, Peltier G, Rey P. 1996. Characterization of a novel drought-induced 34-kDa protein located in the thylakoids of Solanum tuberosum L. plants. Planta 198(3):471-479 DOI: $10.1007 / \mathrm{bf00620065.}$

Rahimi Y, Bihamta MR, Taleei A, Alipour H, Ingvarsson PK. 2019. Genome-wide association study of agronomic traits in bread wheat reveals novel putative alleles for future breeding programs. BMC Plant Biology 19(1):541 DOI: 10.1186/s12870-019-2165-4.

Ramírez-González RH, Borrill P, Lang D, Harrington SA, Brinton J, Venturini L, Davey M, Jacobs J, van Ex E, Pasha A, Khedikar Y, Robinson SJ, Cory AI, Florio I, Concia L, Juery C, Schoonbeek H, Steuernaqel B, Xiang D, Ridout CJ, Chalhoub B, Mayer KFX, Benhamed M, Latrasse D, Bendahmane A; International Wheat Genome Sequencing Consortium, Wulff BBH, Appels R, Tiwari V, Datla R, Choulet E, Pozniak CJ, Provart NJ, Sharpe AG, Paux E, Spannagl M, Bräutiqam A, Uauy C. 2018. The transcriptional landscape of polyploid wheat. Science 361(6403):6403-6089 DOI: 10.1126/science.aar6089. 
481 Rey P, Gillet B, Römer S, Eymery F, Massimino J, Peltier G, Kuntz M. 2000. Over-expression 482 of a pepper plastid lipid-associated protein in tobacco leads to changes in plastid 483 ultrastructure and plant development upon stress. The Plant Journal 21:483-494 DOI: 10.1046/j.1365-313x.2000.00699.x.

Simkin AJ, Moreau H, Kuntz M, Pagny G1, Lin C, Tanksley S, James MC. 2008. An investigation of carotenoid biosynthesis in Coffea canephora and Coffea arabica. J. Plant Physiology 165(10):1087-1106 DOI: 10.1016/j.jplph.2007.06.016.

Singh DK, Maximova SN, Jensen PJ, Lehman BL, McNellis TW. 2010. FIBRILLIN4 is required for plastoglobule development and stress resistance in apple and Arabidopsis. Plant Physiology 154(3):1281-1293 DOI: 10.1104/pp.110.164095.

Singh DK, McNellis TW. 2011. Fibrillin protein function: the tip of the iceberg? Trends in Plant Science 16(8):432-441 DOI: 10.1016/j.tplants.2011.03.014.

Ting JTL, Wu SS, Ratnayake C, Huang AH. 1998. Constituents of the tapetosomes and elaioplasts in Brassica campestris tapetum and their degradation and retention during microsporogenesis. The Plant Journal 16:541-551 DOI: 10.1046/j.1365-313x.1998.00325.x.

Vidi PA, Kanwischer M, Baginsky S, Austin JR, Csucs G, Dörmann P, Kessler F, Bréhélin C. 2006. Tocopherol cyclase (VTE1) localization and vitamin E accumulation in chloroplast plastoglobule lipoprotein particles. Journal of Biological Chemistry 281:11225-11234 DOI: 10.1074/jbc.M511939200.

Willems, E., Leyns, L., and Vandesompele, J. 2008. Standardization of real-time PCR gene expression data from independent biological replicates. Analytical Biochemistry 379(1):127-129 DOI: 10.1016/j.ab.2008.04.036.

Yang Y, Sulpice R, Himmelbach A, Meinhard M, Christmann A, Grill E. 2006. Fibrillin expression is regulated by abscisic acid response regulators and is involved in abscisic acidmediated photoprotection. Proceedings of the National Academy of Sciences of the United States of America 103(15):6061-6066 DOI: www.pnas.org/cgi/doi/10.1073/pnas.0501720103. 
508 Youssef A1, Laizet Y, Block MA, Maréchal E, Alcaraz JP, Larson TR, Pontier D, Gaffé J, Kuntz 509 M. 2010. Plant lipid-associated fibrillin proteins condition jasmonate production under 510 photosynthetic stress. The Plant Journal 61(3):436-445 DOI: 10.1111/j.1365$511 \quad 313 X .2009 .04067 . x$.

512 Ytterberg AJ, Wijk PKJV. 2006. Protein profiling of plastoglobules in chloroplasts and 513 chromoplasts a surprising site for differential accumulation of metabolic enzymes. Plant 514 Physiology 140(3):984-997 DOI: 10.2307/20205663.

515

516 
Figure 1

Phylogenetic relationships, gene structure and functional domain analysis of the TaFBN proteins.

(A) A phylogenetic tree using the neighbor-joining method in MEGA7, with bootstrap values of 1,000 , was constructed to determine whether the exon-intron distribution patterns correlated with the phylogenetic classification of TaFBN (the same phylogenetic tree is also shown in Fig 2 and 4). (B) The coding sequences (CDS) of exons are represented by yellow boxes, the introns are represented by lines, and the untranslated regions (UTRs) are indicated by blue boxes. (C) The conserved domains of the TaFBN proteins were identified using the Conserved Domain Database (CDD) of NCBI against the Pfam v30.0 database ( https://www.ncbi.nlm.nih.gov/Structure/cdd/wrpsb.cgi ).
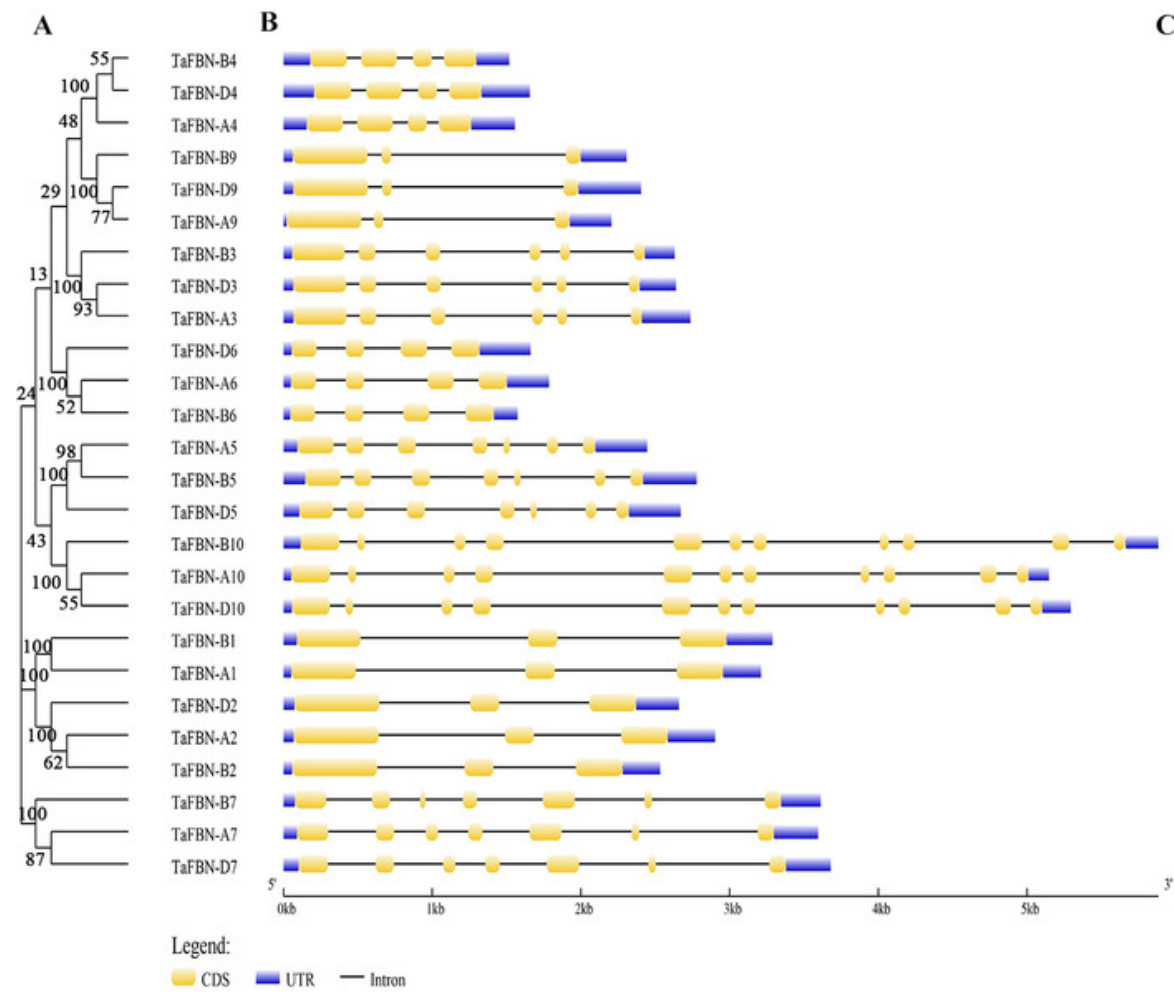

C
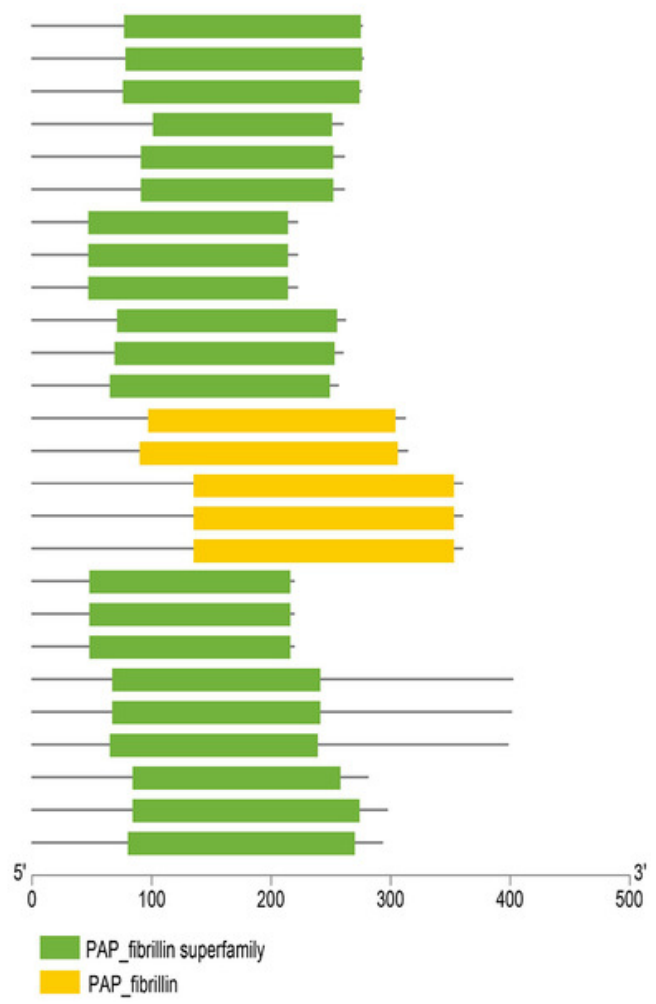
Figure 2

The motif distribution of wheat FBN proteins.

(A) The phylogenetic tree of TaFBN genes was constructed using the neighbor-joining method in MEGA7, with bootstrap values of 1,000. (B) The conserved motifs were predicted using Multiple Em for Motif Elicitation (MEME) (http://alternate.meme-suite.org/). The box length indicates the number of amino acids in the motif.

A

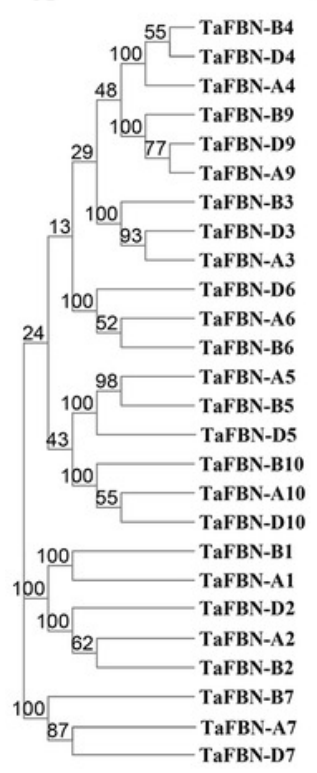

B

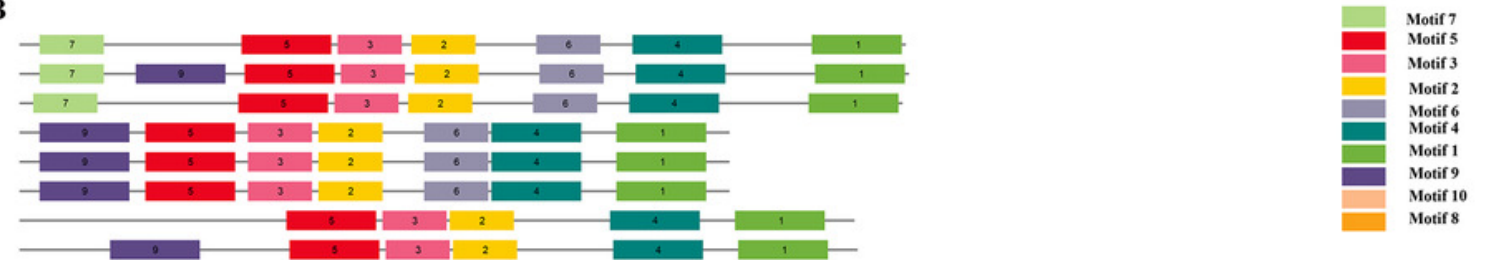


Figure 3

Phylogenetic analysis among 183 FBN proteins in different species.

The FBN proteins are clustered Triticum aestivum, Oryza sativa, Sorghum bicolor, Zea mays, Panicum hallii, Panicum virgatum, Setaria italica, Hordeum vulgare, Arabidopsis thaliana, and Brassica oler. The phylogenetic tree was inferred using the neighbor-joining method in MEGA7, with bootstrap values of 1,000. Bootstrap values are indicated at the nodes, where asterisks indicate values $>99 \%$. The low support nodes $(<50)$ were collapsed and the high support nodes ( $>99$ ) were represented by the symbol $*$ in the phylogenetic tree.
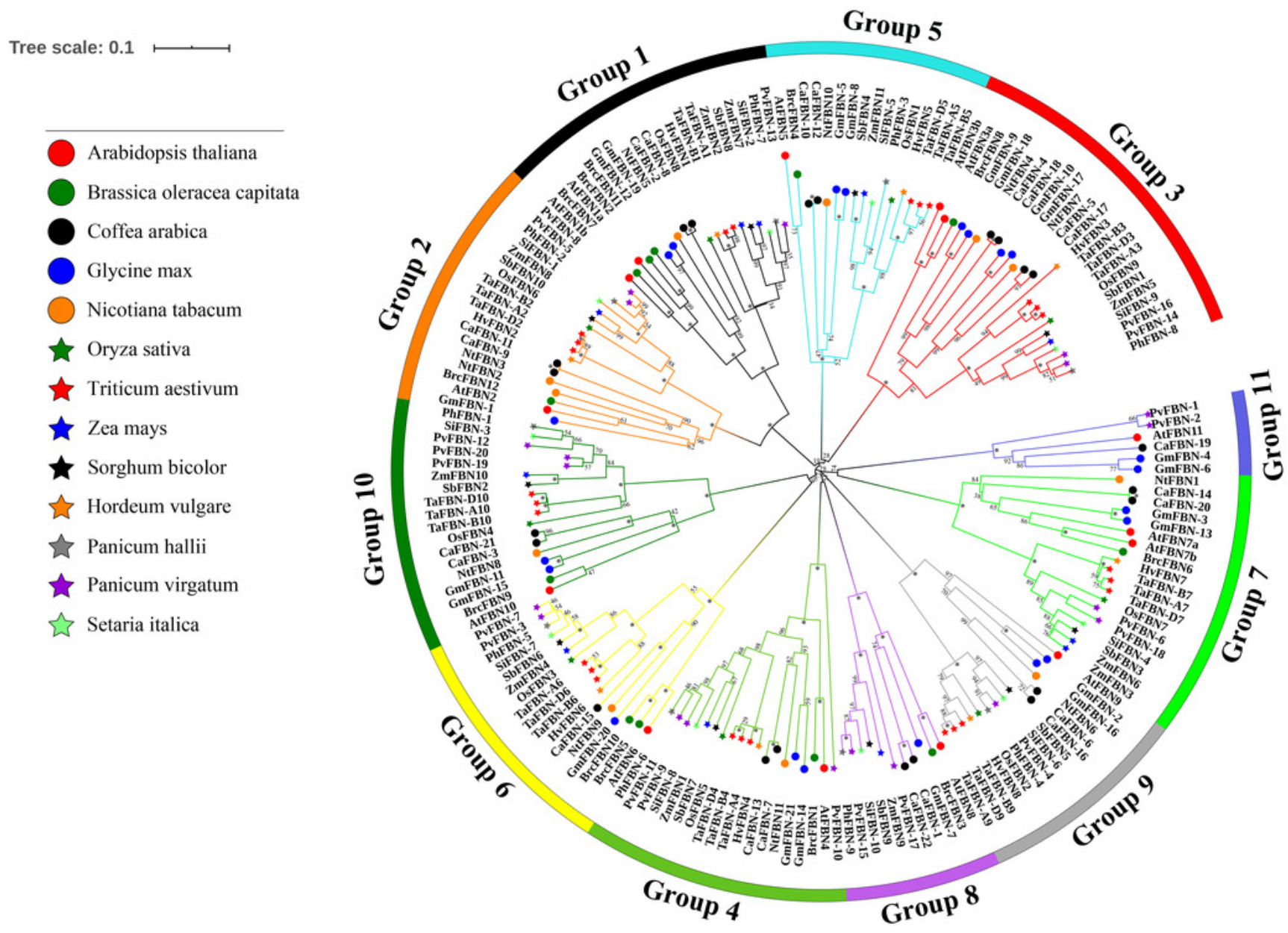
Figure 4

Predicted cis-regulatory elements in the TaFBN gene promoters.

(A) A phylogenetic tree inferred using the neighbor-joining method in MEGA7, with bootstrap values of 1,000 , was constructed to determine whether the exon-intron distribution patterns correlated with the phylogenetic classification of TaFBN. (B) The promoter sequences $(2,000$ bp) upstream of genes were chosen for cis-regulatory element analysis using the PlantCARE online tool (http://www.dna.affrc.go.jp/ PLACE/). Each color indicates a cis-regulatory element.

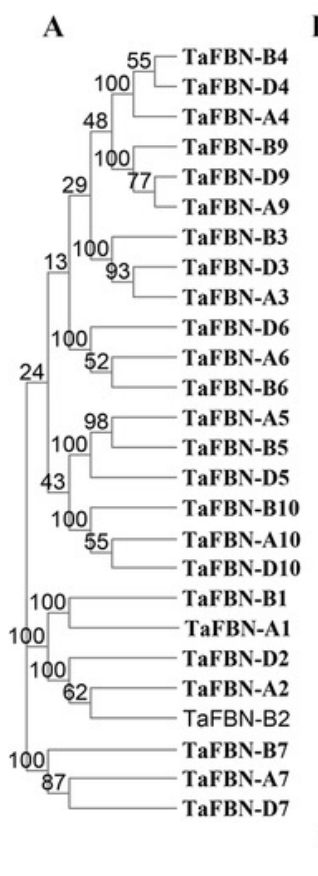

B
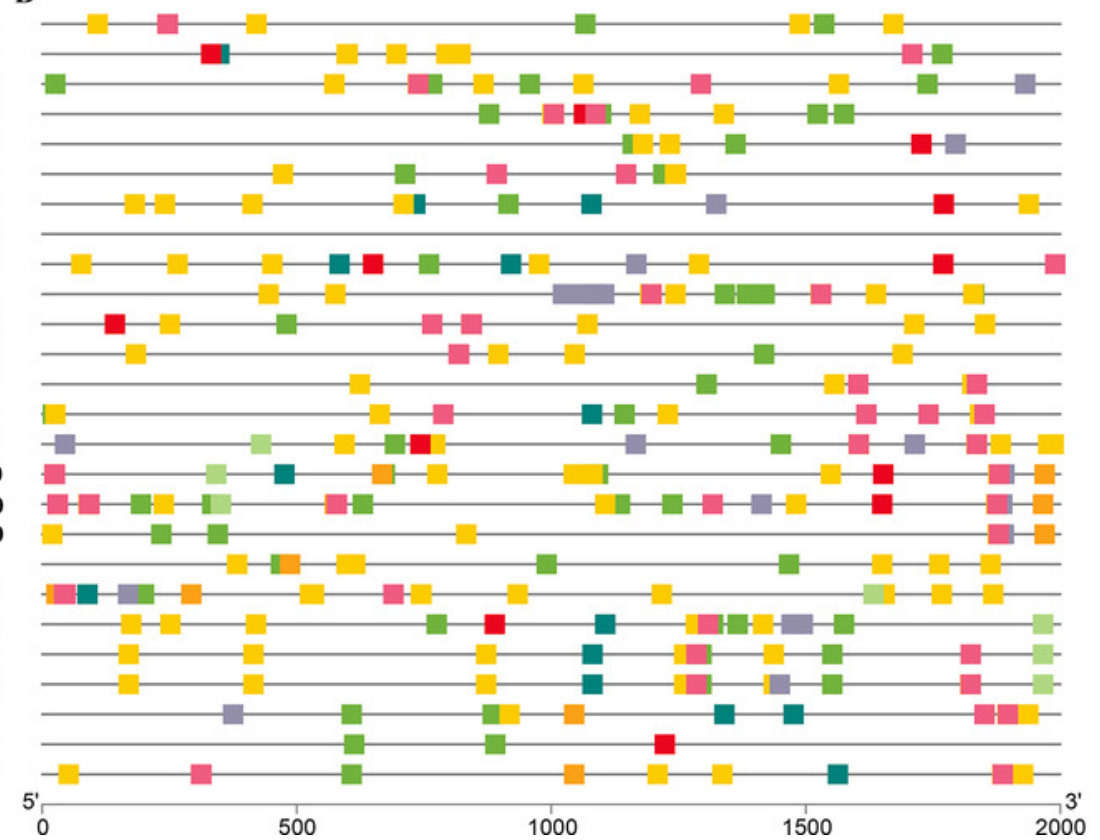

MeJA-responsiveness

light responsiveness

abscisic acid responsiveness

gibberellin-responsiveness

low-temperature responsiveness

drought responsiveness

salicylic acid responsiveness

auxin responsiveness 


\section{Figure 5}

The expression of TaFBNs in various tissues and developmental stages.

(A) Tissue-specific expression of the TaFBN gene family in different wheat tissues; (B) the expression pattern of the TaFBN gene family at different developmental stages. A heatmap was created in TBtools software and based on the expression data. The color scale represents relative expression levels, with red indicating higher levels of expression and blue indicating lower expression levels.
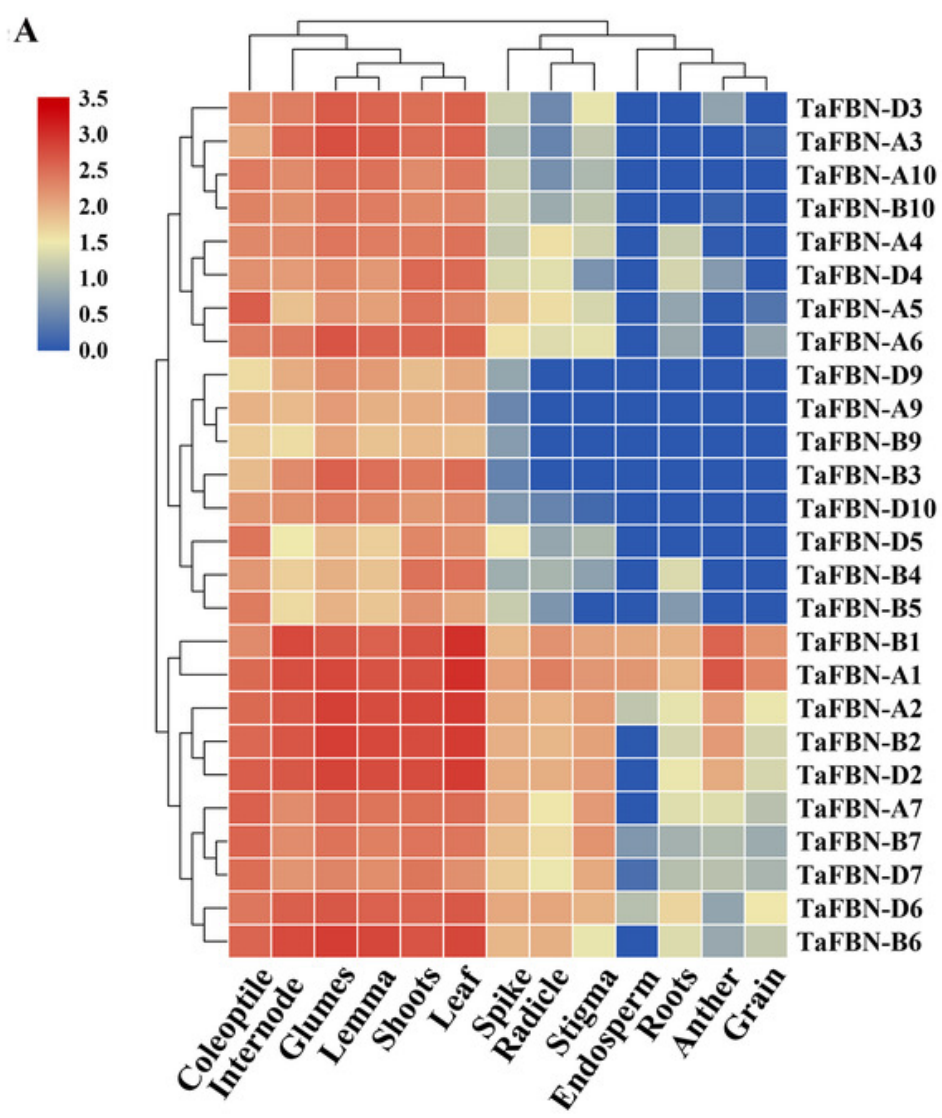

B

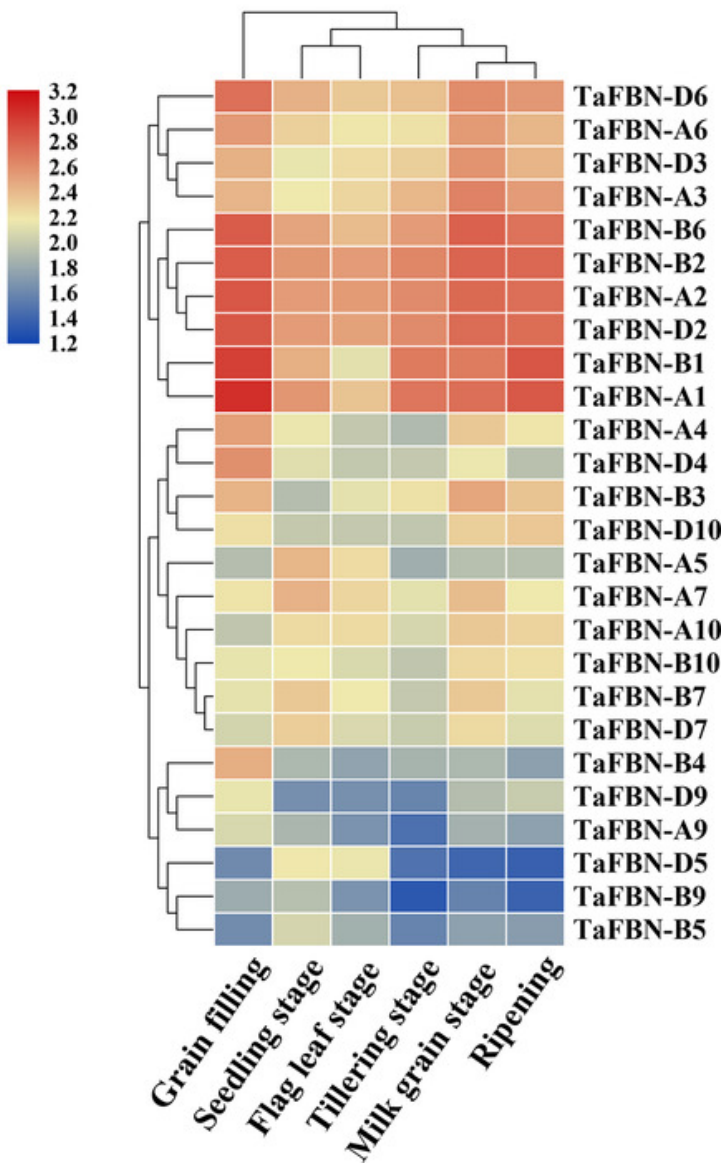


Figure 6

The heat map of expression profiles of TaFBNs in Triticum aestivum under biotic and abiotic stress.

Expression levels are indicated in different colors, with red indicating higher expression levels and blue indicating lower expression levels. 

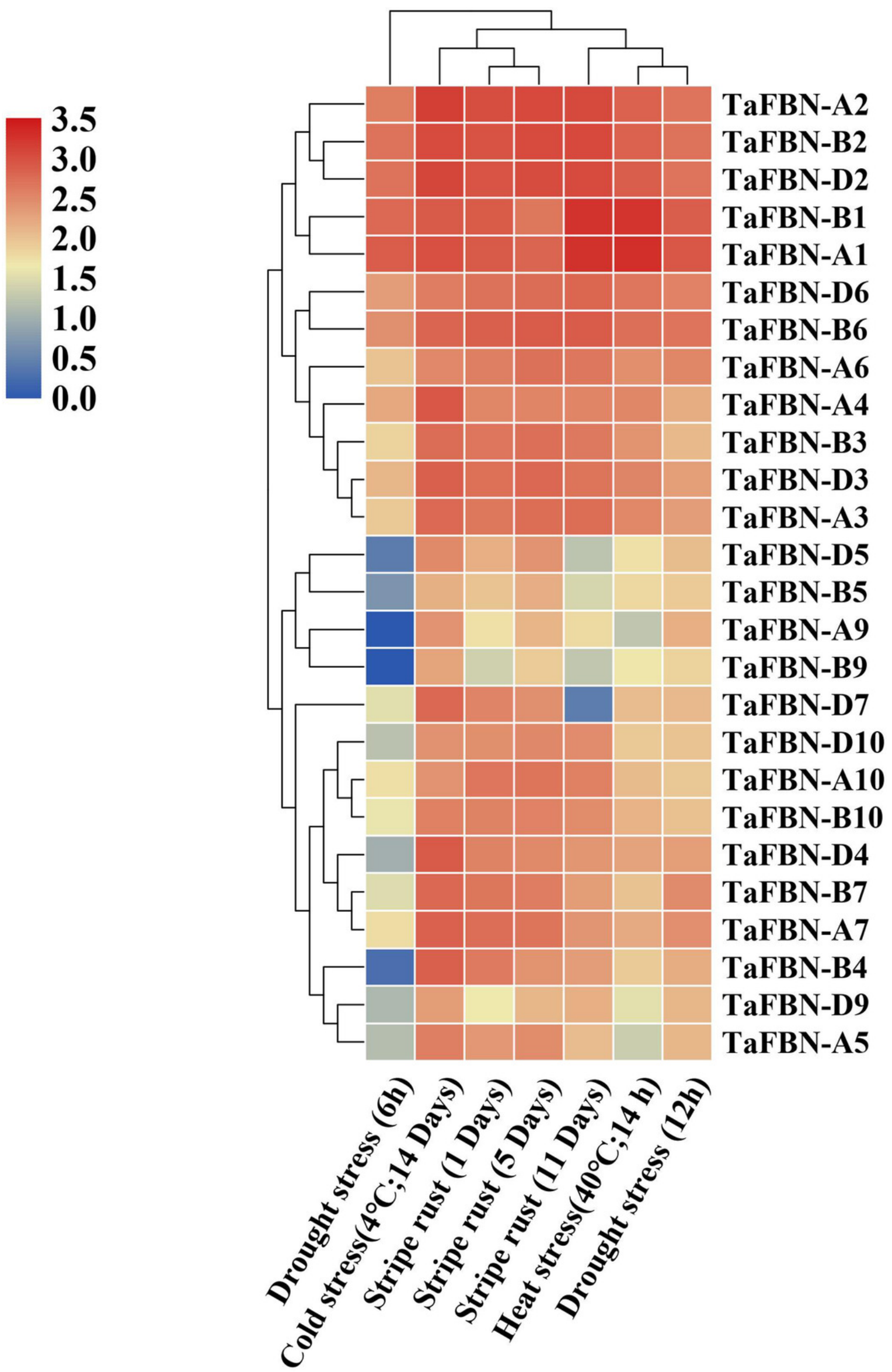


\section{Figure 7}

The expression analysis of TaFBN genes in different tissues and under drought stress using qRT-PCR.

(A) The relative expression levels of TaFBN genes in different tissues. (B) The relative expression levels of TaFBN genes in leaves after drought treatment for $1 \mathrm{~h}$ and $6 \mathrm{~h}$. Each treatment contains three biological replicates. 
A

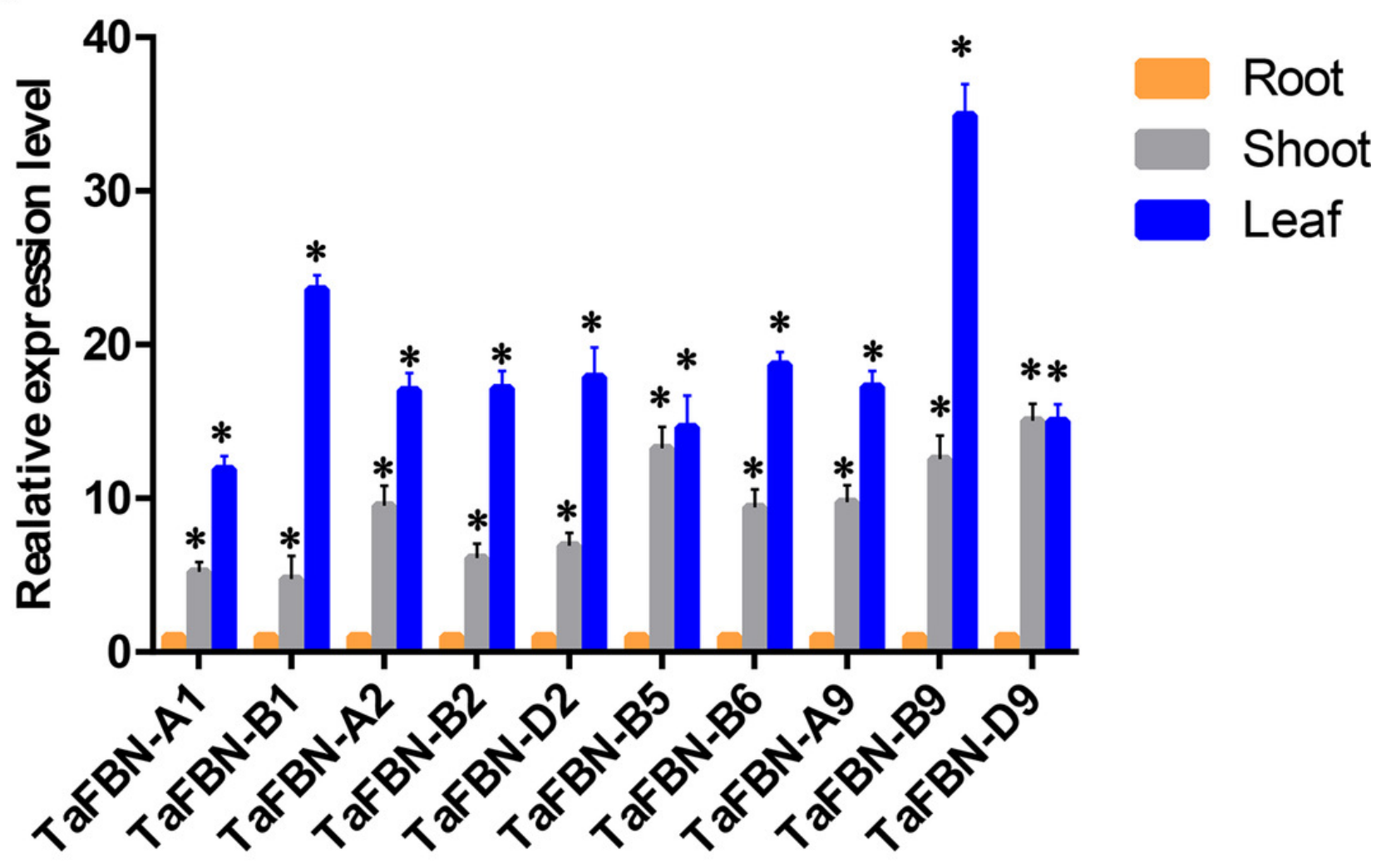

B

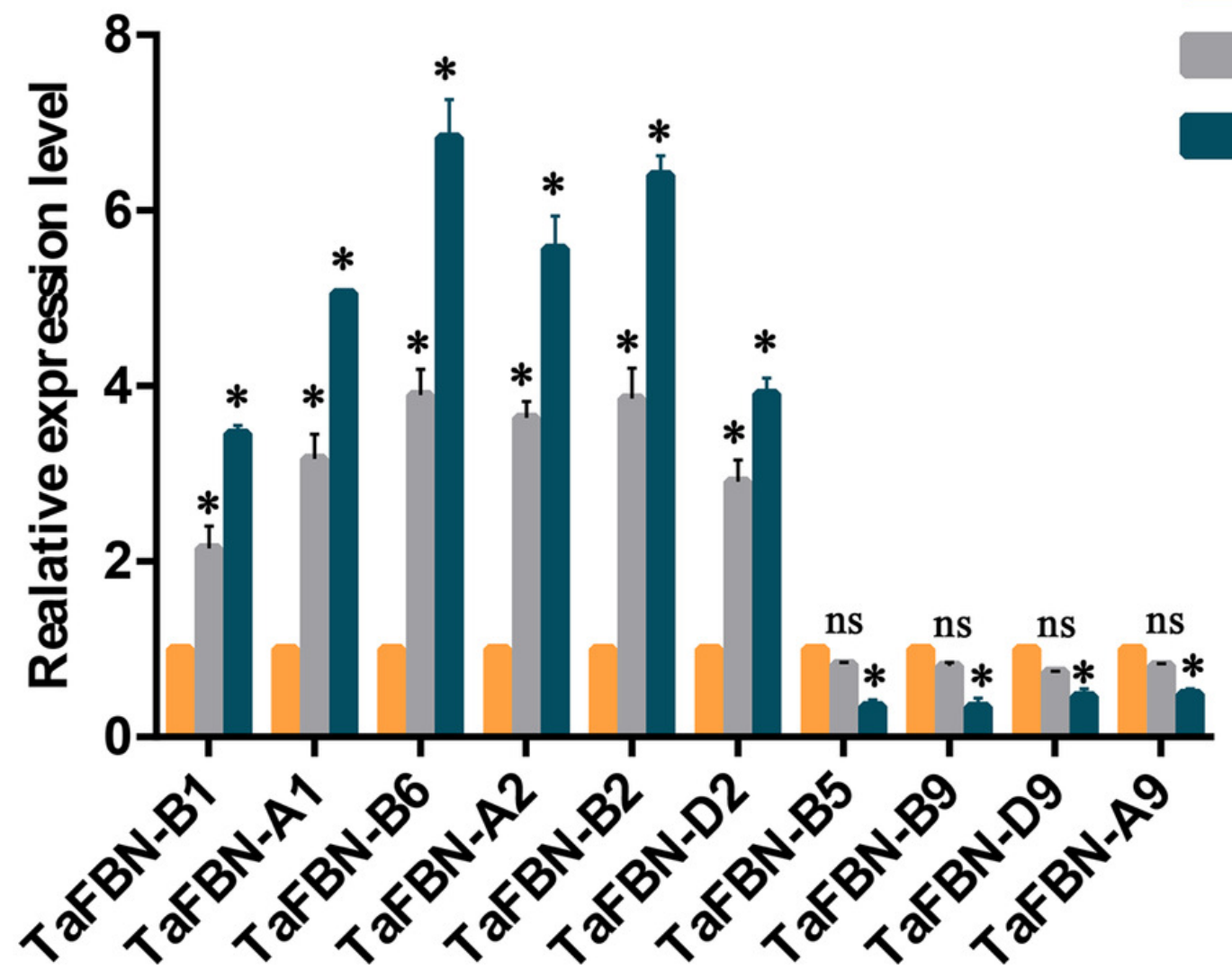

Peerf reviewing PDF | (2019:09:41538:4:0:NEW 18 Apr 2020) 
Table $\mathbf{1}$ (on next page)

Fibrillin (FBN) gene family in Triticum aestivum. 


\begin{tabular}{|c|c|c|c|c|c|c|c|c|c|c|c|c|}
\hline $\begin{array}{l}\text { Gene } \\
\text { name }\end{array}$ & Sequence ID & $\begin{array}{c}\text { Chromosom } \\
\mathrm{e}\end{array}$ & $\begin{array}{l}\text { Genomic } \\
\text { position }\end{array}$ & $\begin{array}{l}\text { Intron } \\
\text { number }\end{array}$ & $\begin{array}{c}\text { Gene } \\
\text { length (aa) }\end{array}$ & $\begin{array}{c}\text { Molecular } \\
\text { weight } \\
(\mathrm{kDa})\end{array}$ & pI & $\begin{array}{c}\text { Predicted } \\
\text { pfam domai } \\
n\end{array}$ & $\begin{array}{c}\text { Subcellular } \\
\text { prediction by } \\
\text { PC }\end{array}$ & $\begin{array}{l}\text { Grand average of } \\
\text { hydropathicity }\end{array}$ & $\begin{array}{c}\text { Signal } \\
\text { peptides }\end{array}$ & $\begin{array}{c}\text { Chloroplast } \\
\text { transit peptides }\end{array}$ \\
\hline $\begin{array}{c}\text { TaFBN- } \\
\text { A1 }\end{array}$ & $\begin{array}{l}\text { TraesCS5A0 } \\
2 \mathrm{G} 164600.1\end{array}$ & Chr5A & $\begin{array}{c}353189098- \\
353192310\end{array}$ & 2 & 314 & 33.06 & 7.77 & $\begin{array}{c}\text { PAP_fibrilli } \\
n\end{array}$ & Chloroplast & 0.039 & NA & $\mathrm{Y}$ \\
\hline $\begin{array}{l}\text { TaFBN- } \\
\text { B1 }\end{array}$ & $\begin{array}{l}\text { TraesCS5B0 } \\
2 \mathrm{G} 162100.1\end{array}$ & Chr5B & $\begin{array}{l}299020240- \\
299020330\end{array}$ & 2 & 312 & 32.94 & 7.77 & $\underset{n}{\text { PAP_fibrilli }}$ & Chloroplast & 0.056 & NA & $\mathrm{Y}$ \\
\hline $\begin{array}{l}\text { TaFBN- } \\
\text { A2 }\end{array}$ & $\begin{array}{l}\text { TraesCS1A0 } \\
\text { 2G193500.1 }\end{array}$ & Chr1A & $\begin{array}{l}350749390- \\
350752293\end{array}$ & 2 & 360 & 38.27 & 4.79 & $\begin{array}{c}\text { PAP_fibrilli } \\
n\end{array}$ & Chloroplast & -0.261 & NA & Y \\
\hline $\begin{array}{l}\text { TaFBN- } \\
\text { B2 }\end{array}$ & $\begin{array}{l}\text { TraesCS1B0 } \\
\text { 2G208500.1 }\end{array}$ & Chr1B & $\begin{array}{c}378397002- \\
378399661\end{array}$ & 2 & 360 & 38.33 & 4.83 & $\underset{n}{P A P \_f i b r i l l i}$ & Chloroplast & -0.294 & NA & Y \\
\hline $\begin{array}{l}\text { TaFBN- } \\
\text { D2 }\end{array}$ & $\begin{array}{l}\text { TraesCS1D0 } \\
\text { 2G197400.1 }\end{array}$ & Chr1D & $\begin{array}{c}278512124- \\
278514657\end{array}$ & 2 & 360 & 38.28 & 4.79 & $\underset{n}{\text { PAP_fibrilli }}$ & Chloroplast & -0.253 & NA & Y \\
\hline $\begin{array}{c}\text { TaFBN- } \\
\text { A3 }\end{array}$ & $\begin{array}{l}\text { TraesCS4A0 } \\
2 \mathrm{G} 272000.1\end{array}$ & Chr4A & $\begin{array}{c}583754471- \\
583757208\end{array}$ & 5 & 261 & 28.59 & 9.34 & $\underset{n}{P A P \_f i b r i l l i}$ & Extracellular & -0.33 & NA & Y \\
\hline $\begin{array}{l}\text { TaFBN- } \\
\text { B3 }\end{array}$ & $\begin{array}{l}\text { TraesCS4B0 } \\
2 \mathrm{G} 042000.1\end{array}$ & Chr4B & $\begin{array}{l}28717109- \\
28719740\end{array}$ & 5 & 260 & 28.48 & 9.61 & $\underset{n}{\text { PAP_fibrilli }}$ & Chloroplast & -0.318 & NA & $\mathrm{Y}$ \\
\hline $\begin{array}{l}\text { TaFBN- } \\
\text { D3 }\end{array}$ & $\begin{array}{l}\text { TraesCS4D0 } \\
2 \mathrm{G} 039200.1\end{array}$ & Chr4D & $\begin{array}{l}16799419- \\
16802059\end{array}$ & 5 & 261 & 28.55 & 9.21 & $\begin{array}{c}\text { PAP_fibrilli } \\
n\end{array}$ & Chloroplast & -0.325 & NA & $\mathrm{Y}$ \\
\hline $\begin{array}{c}\text { TaFBN- } \\
\text { A4 }\end{array}$ & $\begin{array}{l}\text { TraesCS2A0 } \\
2 \mathrm{G} 145900.1\end{array}$ & Chr2A & $\begin{array}{l}90688741- \\
90690297\end{array}$ & 3 & 275 & 28.99 & 8.95 & $\begin{array}{c}\text { PAP_fibrilli } \\
n\end{array}$ & Chloroplast & -0.244 & NA & $\mathrm{Y}$ \\
\hline $\begin{array}{l}\text { TaFBN- } \\
\text { B4 }\end{array}$ & $\begin{array}{l}\text { TraesCS2B0 } \\
2 \mathrm{G} 171300.1\end{array}$ & Chr2B & $\begin{array}{c}144596063- \\
144597581\end{array}$ & 3 & 276 & 29.35 & 9.51 & $\begin{array}{c}\text { PAP_fibrilli } \\
n\end{array}$ & Chloroplast & -0.267 & NA & $\mathrm{Y}$ \\
\hline $\begin{array}{l}\text { TaFBN- } \\
\text { D4 }\end{array}$ & $\begin{array}{l}\text { TraesCS2D0 } \\
2 \mathrm{G} 150500.1\end{array}$ & Chr2D & $\begin{array}{l}93046450- \\
93048107\end{array}$ & 3 & 277 & 29.41 & 9.51 & $\begin{array}{c}\text { PAP_fibrilli } \\
n\end{array}$ & Chloroplast & -0.277 & NA & $\mathrm{Y}$ \\
\hline $\begin{array}{l}\text { TaFBN- } \\
\text { A5 }\end{array}$ & $\begin{array}{l}\text { TraesCS2A0 } \\
2 \mathrm{G} 300200.1\end{array}$ & Chr2A & $\begin{array}{c}515959001- \\
515961447\end{array}$ & 6 & 262 & 28.96 & 9.16 & $\begin{array}{c}\text { PAP_fibrilli } \\
n\end{array}$ & Chloroplast & -0.213 & NA & $\mathrm{Y}$ \\
\hline $\begin{array}{l}\text { TaFBN- } \\
\text { B5 }\end{array}$ & $\begin{array}{l}\text { TraesCS2B0 } \\
\text { 2G316500.1 }\end{array}$ & Chr2B & $\begin{array}{c}451833336- \\
451836114\end{array}$ & 6 & 260 & 28.67 & 9.28 & $\underset{n}{\text { PAP_fibrilli }}$ & Chloroplast & -0.178 & NA & $\mathrm{Y}$ \\
\hline $\begin{array}{l}\text { TaFBN- } \\
\text { D5 }\end{array}$ & $\begin{array}{l}\text { TraesCS2D0 } \\
\text { 2G298100.1 }\end{array}$ & Chr2D & $\begin{array}{l}380429694- \\
380432365\end{array}$ & 6 & 256 & 28.43 & 9.36 & $\underset{n}{\text { PAP_fibrilli }}$ & Chloroplast & -0.2 & NA & $\mathrm{Y}$ \\
\hline $\begin{array}{l}\text { TaFBN- } \\
\text { A6 }\end{array}$ & $\begin{array}{l}\text { TraesCS2A0 } \\
2 \text { G431000.1 }\end{array}$ & Chr2A & $\begin{array}{r}684246511- \\
684248296\end{array}$ & 3 & 219 & 23.78 & 8.8 & $\underset{n}{\text { PAP_fibrilli }}$ & Extracellular & -0.044 & NA & $\mathrm{Y}$ \\
\hline $\begin{array}{l}\text { TaFBN- } \\
\text { B6 }\end{array}$ & $\begin{array}{l}\text { TraesCS2B0 } \\
2 \mathrm{G} 452300.1\end{array}$ & Chr2B & $\begin{array}{l}646214215- \\
646215789\end{array}$ & 3 & 219 & 23.75 & 8.73 & $\begin{array}{c}\text { PAP_fibrilli } \\
n\end{array}$ & Chloroplast & 0.003 & NA & $\mathrm{Y}$ \\
\hline $\begin{array}{l}\text { TaFBN- } \\
\text { D6 }\end{array}$ & $\begin{array}{l}\text { TraesCS2D0 } \\
2 \text { G428800.1 }\end{array}$ & Chr2D & $\begin{array}{c}540824383- \\
540826044\end{array}$ & 3 & 219 & 23.82 & 8.74 & $\underset{n}{\text { PAP_fibrilli }}$ & Chloroplast & -0.031 & NA & $\mathrm{Y}$ \\
\hline $\begin{array}{l}\text { TaFBN- } \\
\text { A7 }\end{array}$ & $\begin{array}{l}\text { TraesCS2A0 } \\
\text { 2G487900.1 }\end{array}$ & $\mathrm{Chr} 2 \mathrm{~A}$ & $\begin{array}{l}722519297- \\
722522892\end{array}$ & 6 & 297 & 32.55 & 5.73 & $\begin{array}{c}\text { PAP_fibrilli } \\
n\end{array}$ & Chloroplast & -0.231 & NA & $\mathrm{Y}$ \\
\hline $\begin{array}{l}\text { TaFBN- } \\
\text { B7 }\end{array}$ & $\begin{array}{l}\text { TraesCS2B0 } \\
\text { 2G515500.1 }\end{array}$ & $\mathrm{Chr} 2 \mathrm{~B}$ & $\begin{array}{c}710281451- \\
710285064\end{array}$ & 6 & 281 & 30.92 & 6.06 & $\underset{\mathrm{n}}{\mathrm{PAP}_{-} \text {fibrilli }}$ & Chloroplast & -0.247 & NA & $\mathrm{Y}$ \\
\hline
\end{tabular}




\begin{tabular}{|c|c|c|c|c|c|c|c|c|c|c|c|c|}
\hline $\begin{array}{c}\text { TaFBN- } \\
\text { D7 }\end{array}$ & $\begin{array}{l}\text { TraesCS2D0 } \\
\text { 2G488200.1 }\end{array}$ & Chr2D & $\begin{array}{c}587697352- \\
587701032\end{array}$ & 6 & 293 & 32.03 & 5.35 & $\begin{array}{c}\text { PAP_fibrilli } \\
n\end{array}$ & Chloroplast & -0.171 & $\mathrm{NA}$ & $\mathrm{Y}$ \\
\hline $\begin{array}{c}\text { TaFBN- } \\
\text { A9 }\end{array}$ & $\begin{array}{l}\text { TraesCS2A0 } \\
2 \text { G413700.1 }\end{array}$ & $\mathrm{Chr} 2 \mathrm{~A}$ & $\begin{array}{c}670791911- \\
670794116\end{array}$ & 2 & 222 & 24.21 & 6.74 & $\underset{n}{\text { PAP_fibrilli }}$ & Extracellular & -0.106 & NA & $\mathrm{Y}$ \\
\hline $\begin{array}{l}\text { TaFBN- } \\
\text { B9 }\end{array}$ & $\begin{array}{l}\text { TraesCS2B0 } \\
2 \text { G432500.1 }\end{array}$ & Chr2B & $\begin{array}{c}621664679- \\
621666987\end{array}$ & 2 & 222 & 24.27 & 7.9 & $\underset{n}{\text { PAP_fibrilli }}$ & Extracellular & -0.123 & NA & $\mathrm{Y}$ \\
\hline $\begin{array}{c}\text { TaFBN- } \\
\text { D9 }\end{array}$ & $\begin{array}{l}\text { TraesCS2D0 } \\
\text { 2G410900.1 }\end{array}$ & $\mathrm{Chr} 2 \mathrm{D}$ & $\begin{array}{c}525935293- \\
525937697\end{array}$ & 2 & 222 & 24.24 & 7.9 & $\underset{n}{\text { PAP_fibrilli }}$ & Extracellular & -0.136 & $\mathrm{NA}$ & $\mathrm{Y}$ \\
\hline $\begin{array}{l}\text { TaFBN- } \\
\text { A10 }\end{array}$ & $\begin{array}{l}\text { TraesCS2A0 } \\
2 \text { G434800.1 }\end{array}$ & $\mathrm{Chr} 2 \mathrm{~A}$ & $\begin{array}{c}686874975- \\
686880122\end{array}$ & 10 & 401 & 43.44 & 9.31 & $\underset{n}{\text { PAP_fibrilli }}$ & Extracellular & -0.16 & NA & $\mathrm{Y}$ \\
\hline $\begin{array}{c}\text { TaFBN- } \\
\text { B10 }\end{array}$ & $\begin{array}{l}\text { TraesCS2B0 } \\
2 \mathrm{G} 455900.1\end{array}$ & $\mathrm{Chr} 2 \mathrm{~B}$ & $\begin{array}{c}650399573- \\
650405456\end{array}$ & 10 & 402 & 43.59 & 9.19 & $\underset{n}{\text { PAP_fibrilli }}$ & Extracellular & -0.182 & NA & $\mathrm{Y}$ \\
\hline $\begin{array}{l}\text { TaFBN- } \\
\text { D10 }\end{array}$ & $\begin{array}{l}\text { TraesCS2D0 } \\
2 \mathrm{G} 432600.1\end{array}$ & Chr2D & $\begin{array}{c}544665056- \\
544670351\end{array}$ & 10 & 398 & 43.12 & 9.11 & $\underset{n}{\text { PAP_fibrilli }}$ & Extracellular & -0.152 & NA & $\mathrm{Y}$ \\
\hline
\end{tabular}

